\title{
Assessment of Optimal Infusion Condition for Thunbergia laurifolia Tea by using Response Surface Methodology
}

\author{
Piyanuch ROJSANGA ${ }^{1}$, Puriwat JIEWATAKUNTUM ${ }^{1}$, \\ Waree LIMWIKRANT ${ }^{2}$ and Kotchaphan CHOOLUCK ${ }^{2, *}$ \\ ${ }^{I}$ Department of Pharmaceutical Chemistry, Faculty of Pharmacy, Mahidol University, \\ Bangkok 10400, Thailand \\ ${ }^{2}$ Department of Manufacturing Pharmacy, Faculty of Pharmacy, Mahidol University, \\ Bangkok 10400, Thailand
}

('Corresponding author's e-mail: kotchaphan.cho@mahidol.edu, kotchaphan.cho@gmail.com)

Received: 28 May 2018, Revised: 6 October 2018, Accepted: 16 November 2018

\begin{abstract}
According to the National List of Essential Medicines of Thailand, the Thunbergia laurifolia (TL) tea is categorized as antipyretic and detoxifying herbal medicine. This tea has also been used for the treatment of drug addiction and smoking cessation. However, suggested infusion conditions were varied which may result in variations in extracted active contents and bioactivities. In this study, the infusion condition that maximized extraction of caffeic acid (CA) and rosmarinic acid (RA), the major markers of TL tea, was assessed by using response surface methodology (RSM). The contents of markers were analyzed by a validated high-performance liquid chromatographic method. To evaluate the extraction efficiency, the marker contents obtained by preparing the tea under the optimal condition were compared to those obtained by aqueous extraction process. The results demonstrated that the marker contents varied considerably according to infusion variables; time, temperature and volume (150 - $250 \mathrm{~mL})$. By using RSM, it was successfully found that the optimal condition for the tea $(3 \mathrm{~g})$ was as follows: $200 \mathrm{~mL}$ of boiling water and infusion time of $10 \mathrm{~min}$. More importantly, by using infusion method, the major portion of markers remained in the tea powder implying poor extraction efficiency of the method. This result suggested that the use of TL extract would be benefit in terms of quality and efficacy. The optimal infusion condition could be utilized in clinical studies to find an effective oral dose range of markers. Ultimately, the obtained information could be used to determine the oral dose of TL extract.
\end{abstract}

Keywords: Caffeic acid, Infusion condition, Response surface methodology, Rosmarinic acid, Thunbergia laurifolia

\section{Introduction}

Thunbergia laurifolia (TL) is a Thai medicinal herb also known as "Rang Cheud". According to National List of Essential Medicines of Thailand, the TL tea has been categorized as antipyretic and detoxifying medicine for poisonings from insecticides [1,2], lead [3], cadmium [4] and ethanol [5]. It was found that the aqueous extract of TL leaves exhibited the highest phenolic content and antioxidant activity comparing to ethanol and acetone extracts [6]. The major active markers of TL tea leave and its aqueous extract were caffeic acid (CA) and rosmarinic acid (RA) [7,8].

Several other biological effects of TL extracts and its markers, especially for RA, have been extensively investigated and reported, such as antioxidant [9], cognitive improvement [10], and antidepressive-like effects [11]. Furthermore, this plant alone or in combination with other medicinal plants has been traditionally and clinically used in the treatment of drug addiction and smoking cessation. Its 
http://wjst.wu.ac.th

efficacy and mechanism studies have been reported for the treatment of drug addiction [12,13], while the scientific data relating to the use in smoking cessation was limited. Recently, patents relating to the use of aqueous extract of leaves of lemon balm (Melissa officinalis) have been launched [14,15]. The plant contained the same major active compounds as TL, CA and RA [16], which could be implied that the aqueous extracts of TL may also have a potential use in the treatment of smoking cessation.

In Thailand, the TL tea products have been manufactured and used as alternative medicines at some hospitals. At Wang-Nam-Yen hospital, Sa Kaeo province, Thailand, the tea has been extensively used for detoxification of insecticides and the treatment of smoking cessation. The tea was provided in a single unit dose as a sachet $(3 \mathrm{~g})$, designed for infusion under non-stirring condition. However, it was found that suggested infusion conditions by pharmacists were varied as follows: infusion time of 5 - 15 min and 120 - $250 \mathrm{~mL}$ of warm or boiling water. While the condition recommended in the National List of Essential Medicines were as follows: $120-200 \mathrm{~mL}$ of hot water, without suggested infusion time [1].

Several previous studies demonstrated that extraction of active compounds from herbal tea was influenced by infusion variables such as infusion time, water temperature and volume. In addition, these parameters also affected the stability of active compounds [17-19]. For TL tea, the varied infusion condition could also contribute to variations in extracted marker contents and bioactivities. Since the therapeutic efficacy or biological activities were directly correlated to the amounts of active ingredients [20], the optimal infusion condition of TL tea should be assessed and employed to achieve the optimal efficacy. Although this tea has been used for decades, the information relating to its optimal infusion condition has not yet been investigated.

The conventional method to study the optimization condition was the 1-factor-at-a-time approach which is time-consuming and cannot explore interactions between variables. Response surface methodology (RSM) based on Box-Behnken design (BBD) is an effective technique to overcome these limitations. The BBD requires 3 levels of each variable, which results in fewer experimental trials to evaluate multiple variables and their interactions [21]. Therefore, this study aimed to employ a RSM based on BBD to optimize the infusion conditions for TL tea, in order to achieve the maximum contents of its active markers in the tea solution. The tea product of Wang Nam Yen hospital was used as a model for optimization. The contents of CA and RA were analyzed by a validated high-performance liquid chromatographic (HPLC) method. The preliminary evaluation of the extraction efficiency showed the marker contents obtained from preparing the tea under the optimal condition were comparable to those obtained by aqueous extraction process. Furthermore, the variation of active contents in plant material used for preparing the tea products was also investigated by aqueous extraction process.

\section{Materials and methods}

\section{Chemicals and reagents}

Reference standards of CA and RA were purchased from Sigma-Aldrich (MO, USA). HPLC grade of acetonitrile and methanol were supplied by Honeywell (NJ, USA) and Fisher chemical (Loughborough, UK), respectively. Analytical grade of glacial acetic acid was provided by Ajax Finechem (MA, USA). The deionized water was obtained from Thai Nakorn Patana (Nonthaburi, Thailand). Two lots of commercial sachets containing $3 \mathrm{~g}$ of finely ground dried leaves of TL were purchased from Wang Nam Yen hospital, Sa Kaeo province, Thailand: Lot no. 034/018/59 (Lot A) and Lot no. 034/009/59 (Lot B). The tea from Lot A was evaluated for weight variation and used to optimize the infusion condition, while the investigation of particle size and preparation of TL extract by aqueous extraction process were performed for both Lot A and Lot B.

\section{Evaluation of weight variation and particle size}

A total of 20 sachets of Lot A were randomly selected and weighed individually. Then, the contents of each sachet were removed and the emptied sachets were individually accurately weighed. The net weight of tea powder content was determined by subtracting the weight of the emptied sachet from the weight of intact sachet. The percentage deviation from the average weight $(\% \mathrm{WV})$ was assessed according to this equation: $\% \mathrm{WV}=\left[\left(\mathrm{W}_{\text {ind }}-\mathrm{W}_{\mathrm{av}}\right) / \mathrm{W}_{\mathrm{av}}\right] \times 100 \%$, where $\mathrm{W}_{\text {ind }}$ and $\mathrm{W}_{\mathrm{av}}$ are individual weight 
http://wjst.wu.ac.th

and average weight, respectively. The \% WV of each sachet should be less than $7.5 \%$ [22]. After the experiment, all of tea powders were mixed and used for particle size determination. For Lot B, a total of 20 sachets were also randomly selected and mixed before measuring the particle size.

Mean particle size was measured by the laser diffraction scattering method (Mastersizer 2000, Malvern, UK). Prior to the measurement, the TL powder was diluted with double-distilled water to a suitable scattering intensity and redispersed by handshaking before the measurement.

\section{Multivariate optimization}

Since the previous studies demonstrated that infusion variables which were infusion time, water temperature and volume affected the component levels of tea solutions [17-19], therefore, these variables were chosen to optimize infusion condition of TL tea. The studied range for each variable was as follows: infusion time of 5 - $15 \mathrm{~min}$, water volume of $150-250 \mathrm{~mL}$ and water temperature of $80-100{ }^{\circ} \mathrm{C}$. These ranges were selected based on the recommended and actual-use conditions employed by patients. In this study, the boiling water temperature was approximately considered as $100{ }^{\circ} \mathrm{C}$. Once the water reached the boiling point, it was further heated for at least $5 \mathrm{~min}$ before using in the experiment. All experiments were performed at a controlled room temperature of $30 \pm 2{ }^{\circ} \mathrm{C}$.

Table 1 Variables, experimental levels and marker contents in TL tea solutions prepared according to Box-Behnken Design trials.

\begin{tabular}{llllll}
\hline \multirow{2}{*}{ Experiment } & \multicolumn{3}{c}{ Decodified variables } & \multicolumn{2}{c}{ Content $(\mathbf{m g}$ per $\mathbf{1}$ g of TL tea)** } \\
\cline { 2 - 6 } & $\begin{array}{l}\text { Time } \\
(\mathbf{m i n})\end{array}$ & $\begin{array}{l}\text { Temperature } \\
\left({ }^{\circ} \mathbf{C}\right) *\end{array}$ & $\begin{array}{l}\text { Volume } \\
(\mathbf{m L})\end{array}$ & $\mathbf{C A}$ & RA \\
\hline 1 & 5 & 80 & 200 & $0.010 \pm 0.001$ & $0.169 \pm 0.007$ \\
2 & 15 & 80 & 200 & $0.031 \pm 0.003$ & $0.252 \pm 0.011$ \\
3 & 5 & 100 & 200 & $0.035 \pm 0.003$ & $0.672 \pm 0.015$ \\
4 & 15 & 100 & 200 & $0.034 \pm 0.005$ & $0.684 \pm 0.012$ \\
5 & 5 & 90 & 150 & $0.011 \pm 0.0003$ & $0.202 \pm 0.004$ \\
6 & 15 & 90 & 150 & $0.029 \pm 0.0002$ & $0.357 \pm 0.006$ \\
7 & 5 & 90 & 250 & $0.021 \pm 0.004$ & $0.196 \pm 0.010$ \\
8 & 15 & 90 & 250 & $0.024 \pm 0.001$ & $0.243 \pm 0.012$ \\
9 & 10 & 80 & 150 & $0.019 \pm 0.001$ & $0.365 \pm 0.002$ \\
10 & 10 & 100 & 150 & $0.032 \pm 0.002$ & $0.683 \pm 0.006$ \\
11 & 10 & 80 & 250 & $0.017 \pm 0.001$ & $0.352 \pm 0.001$ \\
12 & 10 & 100 & 250 & $0.033 \pm 0.001$ & $0.716 \pm 0.006$ \\
13 & 10 & 90 & 200 & $0.025 \pm 0.004$ & $0.320 \pm 0.006$ \\
14 & 10 & 90 & 200 & $0.023 \pm 0.001$ & $0.343 \pm 0.012$ \\
15 & 10 & 90 & 200 & $0.025 \pm 0.003$ & $0.312 \pm 0.006$ \\
\hline
\end{tabular}

* Boiling water temperature was considered as $100^{\circ} \mathrm{C}$.

** Data expressed as Mean $\pm \mathrm{SD} ; n=3$. 
http://wjst.wu.ac.th

To optimize the infusion condition, one batch of the TL tea (Lot A) was used in order to avoid variations in composition of the plant. The weight of sachets used in this study was within $5 \%$ of the mean sachet weight corresponded to 2.85 - $3.15 \mathrm{~g}$ of dried leaves. A 3-level Box-Behnken design (BBD) with 15 trials, including 3 replicates at the center point was used to assess the condition that maximized CA and RA contents in the tea solutions. Each trial was performed in triplicate. The detailed levels are shown in Table 1. For the preparation of the tea solution, a sachet was weighed and placed in a glass bottle $(350 \mathrm{~mL})$. Then, the water was added, with the sachet staying totally immersed in the water, and the infusion remained at rest. After infusion period, the sachet was immediately removed and filtered through a filter paper (Whatman no. 1). The solution was evaporated according to the procedure described by $\mathrm{N}$ Ruangpayungsak [12]. The solution was poured into an evaporating dish and then evaporated on a water bath $\left(70 \pm 2{ }^{\circ} \mathrm{C}\right)$. After obtaining a small volume of concentrated solution (approximately $10 \mathrm{~mL}$ ), the extract was transferred into a known weight of glass bottle $(15 \mathrm{~mL})$ and further evaporated on water bath until obtaining a constant weight (total weight). The extract was kept at $-20{ }^{\circ} \mathrm{C}$ until analysis. The net weight of tea extract was calculated by subtracting the weight of empty bottle from the total weight. During the experiment, leak sachets were removed and excluded from analysis.

Before the analysis was performed, each dried extract was thawed unassisted at room temperature and reconstituted with an appropriate amount of deionized water. The sample was sonicated until no particles were visually observed (less than $10 \mathrm{~min}$ ). Then, the extract solution was filtered using PTFE syringe filter (13 mm diameter, $0.22 \mu \mathrm{m}$ pore size, Membrane solution, TX, USA) and analyzed for CA and RA contents by HPLC.

\section{Aqueous extract preparation}

In order to conduct the preliminary evaluation of the extraction efficiency, the marker contents obtained from infusion and aqueous extraction processes were compared. The aqueous extracts were prepared according to the experimental procedure described by Ruangpayungsak [8]. One batch of the TL tea (Lot A) was used in this study to avoid variations in composition of the plant. An accurately weighed of TL tea powder $(2.5 \mathrm{~g})$ from Lot A was transferred into a glass tube and $25 \mathrm{~mL}$ of deionized water was added $(1: 10 \mathrm{w} / \mathrm{v})$. The tube was placed in an aluminum vessel $(500 \mathrm{~mL})$ containing $200 \mathrm{~mL}$ of water. The vessel was then placed on a heating plate set to $90{ }^{\circ} \mathrm{C}$ for $2 \mathrm{~h}$. After that, the mixture was centrifuged at $5,000 \mathrm{rpm}$ for $15 \mathrm{~min}$ and filtered through a Whatman filter paper no. 1. The extraction process was repeated for 3 times. The filtrates were combined and evaporated under the same experimental procedure described above. The extracts were kept at $-20{ }^{\circ} \mathrm{C}$ until analysis. The experiment was performed in triplicate. Furthermore, to evaluate the variation in active contents of plant materials, the marker contents extracts obtained from Lot A and Lot B were compared.

\section{Analytical method validation for the determination of CA and RA}

The HPLC (Waters corporation, MA, USA) instrument was equipped with a binary pump (model 1525), an autosampler (model 717), a dual wavelength UV detector (model 2487) and a column compartment. Samples were separated on a Xterra ${ }^{\circledR} \mathrm{C}_{18}$ reversed-phase column $\left(150 \times 3.9 \mathrm{~mm}^{2}, 5 \mu \mathrm{m}\right.$, Waters, USA). The detection wavelength was $330 \mathrm{~nm}$. The mobile phase consisted of $0.5 \%(\mathrm{v} / \mathrm{v})$ glacial acetic acid (A) and acetonitrile (B). The gradient elution was performed as follows: 0.0 - $15.0 \mathrm{~min}(15 \%$ B), $15.1-19.0 \min (15-25 \%$ B), $19.1-23.0 \min (25-15 \%$ B) and $23.1-25.0 \min (15 \%$ B). The column temperature was controlled at $30 \pm 2{ }^{\circ} \mathrm{C}$. The injection volume was $20 \mu \mathrm{l}$ and the flow rate was maintained at $1 \mathrm{~mL} / \mathrm{min}$ with a run time of $25 \mathrm{~min}$. The integrations were performed using Empower 2 software (Waters, MA, USA).

The chromatographic method was validated according to the Association of Official Analytical Chemistry (AOAC) guidelines for single-laboratory validation of chemical methods for dietary supplements and botanicals [23]. Evaluation parameters were specificity, linearity, system suitability, intra- and inter day accuracy and precision. The standard stock solutions of CA and RA were prepared in methanol at a concentration of $1 \mathrm{mg} / \mathrm{mL}$ and stored at $-20{ }^{\circ} \mathrm{C}$ for a maximum of $1 \mathrm{month}$. The specificity was evaluated by comparison of the HPLC chromatograms of TL extracts with the standard mixtures and blank samples (15\% Acetronitrile: $85 \%$ Glacial acetic acid solution $(5 \% \mathrm{v} / \mathrm{v}))$. The linearity was 
http://wjst.wu.ac.th

assessed by analyzing the series of standard mixtures of CA and RA at 5 concentration levels $(1,5,10,20$ and $40 \mu \mathrm{g} / \mathrm{mL})$. Each concentration was analyzed in triplicate. The standard curves were achieved by plotting between the concentrations (x-axis) and peak areas of each standard (y-axis). A regression equation of the calibration curve was calculated by regression analysis. The accuracy was examined by recovery of known amounts of standards spiked into the sample solutions $(5,10$ and $20 \mu \mathrm{g} / \mathrm{mL})$. Each concentration was analyzed in triplicate. Repeatability (intra-day precision) and intermediate precision (inter-day precision) were evaluated by analyzing TL extracts on the same day $(n=6)$ and by 2 analysts on 2 different days $(n=12)$, respectively. The relative standard deviation (RSD) was calculated. The system suitability was tested in term of tailing factor, the number of theoretical plates and the relative standard deviation for replicate injections of the standard solution $(n=6)$.

\section{Statistical analysis}

The analysis of variance (ANOVA) was carried out to determine individual linear, quadratic and interaction regression coefficient using Design Expert trial version 10.0 (State Ease, Inc.). The fitness of the polynomial equation to the response was estimated using coefficient of determination $\left(R^{2}\right)$. The terms of polynomial equation was considered significantly different at $p$-value less than $0.05(p<0.05)$.

\section{Results and discussion}

Weight variation and particle size

The average weight of intact sachet and filled content of the TL tea (Lot A) was 3.077 \pm 0.077 and $2.907 \pm 0.082 \mathrm{~g}$, with the \% RSD of 2.50 and $2.83 \%$, respectively, suggesting that the TL tea used in the infusion study had uniform weight and content. The mean particle size values (D50) measured by laser diffraction for Lot A and Lot B were $118.93 \mu \mathrm{m}(\operatorname{span} 4.67 \mu \mathrm{m})$ and $120.45 \mu \mathrm{m}(\operatorname{span} 6.00 \mu \mathrm{m})$, respectively, which were not significantly different from each other $(p>0.05)$.

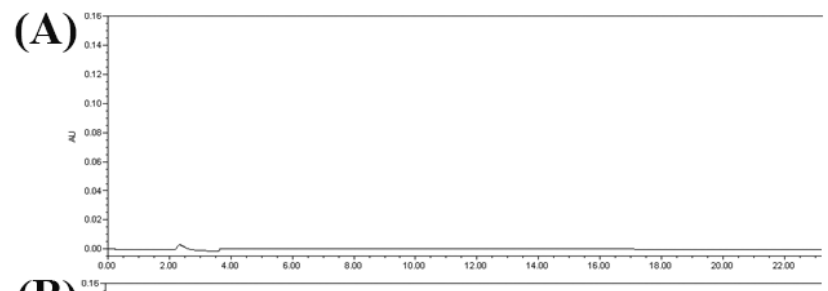

(B)
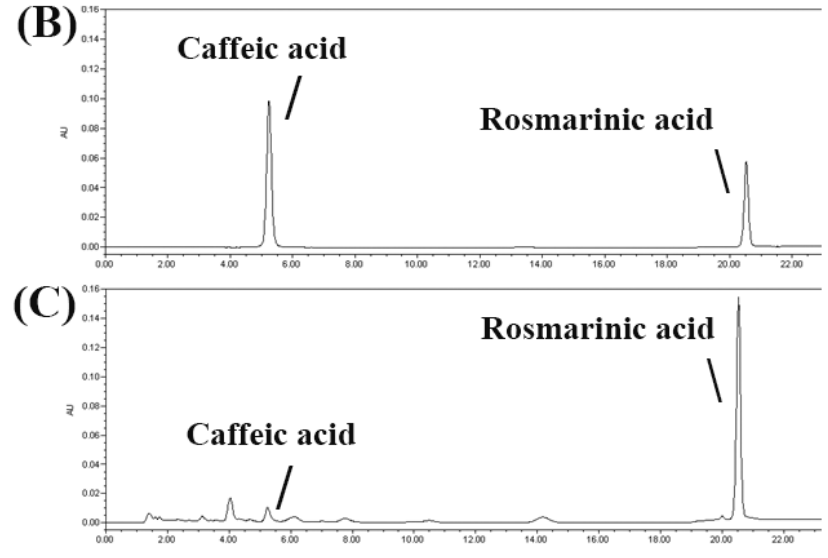

Time (min)

Figure 1 Representative HPLC chromatograms of (A) blank sample (15\% Acetronitrile: $85 \%$ Glacial acetic acid solution $(5 \% \mathrm{v} / \mathrm{v}))$, (B) standard mixture and $(\mathrm{C})$ tea solution prepared under the optimal condition. Peaks of 5.38 and 20.69 min are CA and RA, respectively. 
http://wjst.wu.ac.th

Validation of the chromatographic method

An accurate, simple, and reproducible HPLC method was developed and validated for the determination of CA and RA in TL extracts. No significant interfering peaks from blank sample and standard mixture were observed. Separation of CA and RA was successfully achieved in less than $22 \mathrm{~min}$ with good resolution. The calibration curves for both investigated compounds showed good linearity within the range of $1-40 \mu \mathrm{g} / \mathrm{mL}$. The correlation coefficient was more than 0.999 for all validation batches. The average recovery of CA and RA was $102.8 \pm 1.1$ and $100.5 \pm 2.2 \%$, respectively. The $\%$ RSD for repeatability was less than $1.3 \%$ for CA and less than $0.6 \%$ for RA. Intermediate precision was less than 1.0 and $0.5 \%$ for CA and RA, respectively. For system suitability of CA and RA, the peak tailing factors were less than 1.1 , the number of theoretical plates were more than 5200 , and the $\%$ RSD for replicate injections were less than $0.3 \%$. Figure 1 shows representative HPLC chromatograms of blank sample, standard mixture and extract of TL tea prepared under the optimal infusion condition. The results demonstrated that all of validated parameters were within acceptable ranges for the analytical purposes.

Table 2 Significant regression coefficients for coded variables of quadratic models.

\begin{tabular}{lllll}
\hline Parameters & & Coefficient & Standard error & $\boldsymbol{p}_{\text {-value }} \mathbf{a}^{\mathrm{a}}$ \\
\hline CA & & & & $<.0 .0001$ \\
Intercept & & 0.0239 & $6.28 \mathrm{E}-04$ & $<0.0001$ \\
Time & $\mathrm{x}_{1}$ & $5.15 \mathrm{E}-03$ & $4.62 \mathrm{E}-04$ & $<0.0001$ \\
Temperature & $\mathrm{x}_{2}$ & $7.01 \mathrm{E}-03$ & $4.62 \mathrm{E}-04$ & 0.4232 \\
Volume & $\mathrm{x}_{3}$ & $3.93 \mathrm{E}-04$ & $4.62 \mathrm{E}-04$ & $<0.0001$ \\
Time $\times$ Temperature & $\mathrm{x}_{1} \times \mathrm{x}_{2}$ & $-5.54 \mathrm{E}-03$ & $6.54 \mathrm{E}-04$ & 0.0008 \\
Time $\times$ Volume & $\mathrm{x}_{1} \times \mathrm{x}_{3}$ & $-3.66 \mathrm{E}-03$ & $6.54 \mathrm{E}-04$ & 0.0013 \\
Temperature $\times$ Temperature & $\mathrm{x}_{2}{ }^{2}$ & $3.50 \mathrm{E}-03$ & $6.79 \mathrm{E}-04$ & 0.0080 \\
Volume $\times$ Volume & $\mathrm{x}_{3}{ }^{2}$ & $-2.49 \mathrm{E}-03$ & $6.79 \mathrm{E}-04$ & $<0.0001$ \\
\hline RA & & & & 0.0342 \\
Intercept & & 0.3278 & 0.0205 & $<0.0001$ \\
Time & $\mathrm{x}_{1}$ & 0.0369 & 0.0151 & 0.0046 \\
Temperature & $\mathrm{x}_{2}$ & 0.2019 & 0.0151 & $<0.0001$ \\
Time $\times$ Time & $\mathrm{x}_{1}{ }^{2}$ & -0.0803 & 0.0221 & \\
Temperature $\times$ Temperature & $\mathrm{x}_{2}{ }^{2}$ & 0.1993 & 0.0221 & \\
\hline
\end{tabular}

${ }^{a}$ significant at the $95 \%$ confidence level.

The effect of infusion variables on marker contents

Table 1 shows the studied variables and obtained responses after preparing tea solutions under experimental conditions of BBD. The data was subjected to multivariate analysis and generated regression coefficients of the models for all responses are shown in Table 2. The regression of the 
http://wjst.wu.ac.th

quadratic model was significant at the $95 \%$ confidence level and the residuals were shown to be random. The ANOVA results (Table 3) indicated that the quadratic models showed no lack of fit $(p>0.05)$ suggesting that removing non-significant effects did not affect the model fit. The $\mathrm{R}^{2}$ of multiple correlation coefficients of CA and RA contents were 0.9862 and 0.9661 , respectively, demonstrating that there was a high degree of correlation between observed and predicted values. Therefore, the mathematical model was accepted and further used to explain effects of the infusion variables on extracted marker contents.

Table 3 Analysis of variance of quadratic polynomial models for CA and RA contents.

\begin{tabular}{|c|c|c|c|c|c|}
\hline Sources of variations & Sum of square & DF & Mean square & F-value & $p$-value ${ }^{a}$ \\
\hline \multicolumn{6}{|l|}{$\mathrm{CA}\left(\mathrm{R}^{2}=0.9862\right)$} \\
\hline Regression & $8.56 \mathrm{E}-04$ & 7 & $1.22 \mathrm{E}-04$ & 71.47 & $<0.0001$ \\
\hline Residual error & $1.20 \mathrm{E}-05$ & 7 & $1.71 \mathrm{E}-06$ & & \\
\hline Lack of fit & $7.40 \mathrm{E}-06$ & 5 & $1.48 \mathrm{E}-06$ & 0.65 & 0.6994 \\
\hline Pure error & $4.57 \mathrm{E}-06$ & 2 & $2.29 \mathrm{E}-06$ & & \\
\hline Total SS & $8.68 \mathrm{E}-04$ & 14 & & & \\
\hline \multicolumn{6}{|l|}{$\mathrm{RA}\left(\mathrm{R}^{2}=0.9661\right)$} \\
\hline Regression & 0.5177 & 4 & 0.1294 & 71.30 & $<0.0001$ \\
\hline Residual error & 0.0182 & 10 & $1.82 \mathrm{E}-03$ & & \\
\hline Lack of fit & 0.0177 & 8 & $2.21 \mathrm{E}-03$ & 8.91 & 0.1048 \\
\hline Pure error & $4.95 \mathrm{E}-04$ & 2 & $2.48 \mathrm{E}-04$ & & \\
\hline Total SS & 0.5359 & 14 & & & \\
\hline
\end{tabular}

DF, degree of freedom; $\mathrm{R}^{2}$, coefficient of determination.

a significant at the $95 \%$ confidence level.

It was found that infusion variables significantly affecting the transfer of CA content were infusion time, water temperature and volume, while those for RA content were infusion time and temperature. Figure 2 demonstrates the response surface and contour plots of interaction between volume and infusion time at different water temperatures $\left(80,90\right.$ and $\left.100^{\circ} \mathrm{C}\right)$ on $\mathrm{CA}$ content. The negative quadratic effect of volume on CA content indicated that increasing this variable favored CA extraction up to maximum level, after which lower CA contents were obtained. This degradation effect may be explained by the slower rate of heat loss when larger water volume was used for infusion [17,24].

Three-dimensional response surface and contour plots are illustrated in Figure 3 showing the effects of temperature and infusion time on the responses, while the water volume was kept constant at $200 \mathrm{~mL}$. It was observed that when increasing infusion time and water temperature, the marker contents increased. In particular, when the boiling water was used for infusion, the CA and RA content reached the maximum level at infusion time of 5 and $10 \mathrm{~min}$, respectively. This may because the raising water temperature could increase the solubility and the diffusion coefficient of phenolic compounds, thereby providing higher dissolution rates [25]. In the case of RA, the negative quadratic effect of the infusion time indicated that increasing this variable favored extraction up to maximum level, after which there was a decrease in RA content. Since the long infusion time may result in the degradation of RA, as previously reported that the extraction yield of RA from Thymus vulgaris leaves was sensitive to temperature and exposure time [26]. 

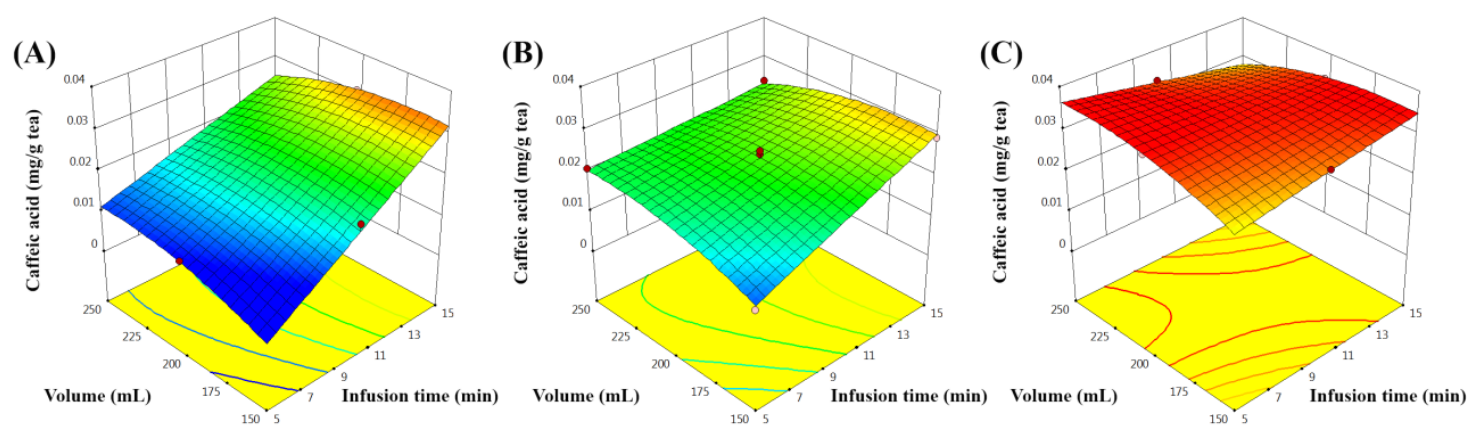

Figure 2 Response surface and contour plots of CA content (mg of CA/g of TL tea) at water temperature of (A) $80{ }^{\circ} \mathrm{C}$, (B) $90{ }^{\circ} \mathrm{C}$ and (C) $100{ }^{\circ} \mathrm{C}$. Variables: Volume $(\mathrm{mL}) \times$ Infusion time $(\mathrm{min})$.
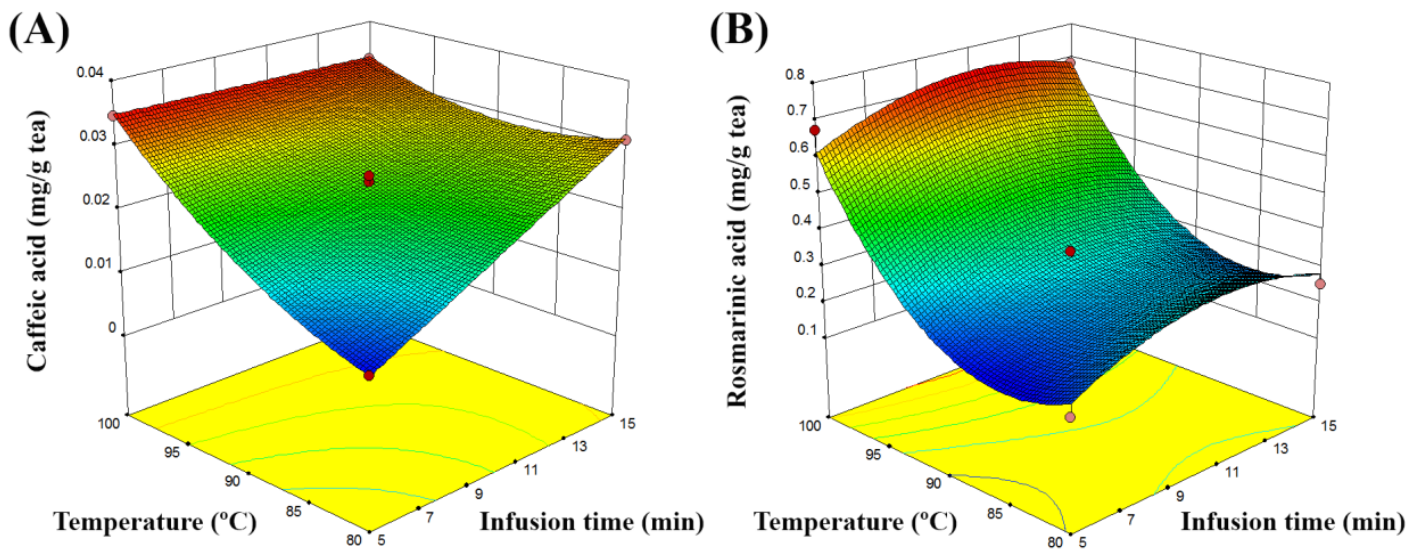

Figure 3 Response surface and contour plots of (A) CA content (mg of CA/g of TL tea) and (B) RA content (mg of RA/g of TL tea). Variables: Temperature $\left({ }^{\circ} \mathrm{C}\right) \times$ Infusion time $(\mathrm{min})$, with the volume fixed at $200 \mathrm{~mL}$.

\section{Optimization of infusion condition for TL tea}

After obtaining mathematical models with a good fit, it was possible to optimize the infusion conditions of TL tea to obtain the maximum marker contents. It was found that the optimal condition was as follows: $190.388 \mathrm{~mL}$ of boiling water and infusion time of $9.986 \mathrm{~min}$ with desirability of 0.916 . For the practical experiment, the condition employed was $200 \mathrm{~mL}$ of boiling water and infusion time of $10 \mathrm{~min}$. At this condition, the predicted content of CA and RA were 0.034 and $0.729 \mathrm{mg}$ per $1 \mathrm{~g}$ of the tea, respectively. The experimental confirmation was performed in triplicate. The results showed that the average CA and RA contents were $0.032 \pm 0.003$ and $0.800 \pm 0.032 \mathrm{mg}$ per $1 \mathrm{~g}$ of the tea, respectively. The $\%$ relative error between the predicted and observed values for CA and RA contents was 6.25 and $8.88 \%$, respectively. Thus, the model was great predictive ability and could be used to assess the optimal infusion condition of TL tea.

As can be seen in Table 1, the RA content obtained from the optimal condition was higher than those obtained from experimental condition no. 4 (Table 1), which performed the infusion in $200 \mathrm{~mL}$ of boiling water for $15 \mathrm{~min}$. The longer infusion time resulted in less amount of RA, thereby implying the 
http://wjst.wu.ac.th

degradation of the marker. These results were in accordance with the previous study as described above [26] and the 3-dimensional response surface and contour plots of Figure 3(B). Therefore, temperature and time should be carefully optimized to obtain optimal yield of RA.

\section{Evaluation of extraction efficiency and variation of TL products}

For the evaluation of extraction efficiency, one batch of the TL tea (Lot A) was used in order to avoid variations in chemical composition. In addition, for the investigation of chemical variation of plant extracts, parameters affecting extraction yield, such as amount of solvent, duration of extraction, and particle size should be carefully controlled to obtain reliable results [27]. In this study, the particle size of TL tea powder of Lot A and Lot B were not significantly different. Therefore, these 2 lots were used for determination of variation of composition.

The average amount of $\mathrm{CA}$ and RA in the aqueous extract prepared by using tea powder of Lot A was $0.447 \pm 0.023$ and $10.148 \pm 0.675 \mathrm{mg}$ per $1 \mathrm{~g}$ of $\mathrm{TL}$ tea powder (Mean $\pm \mathrm{SD}$ ), respectively. As described above, the average CA and RA contents obtained from preparing the tea under optimal infusion condition were 0.032 and $0.800 \mathrm{mg}$ per $1 \mathrm{~g}$ of the tea, respectively. This means that the mount of CA and RA was approximately 7.16 and $7.88 \%$ of those contained in the aqueous extracts, respectively. Although the active markers, especially for RA, could be degraded during the aqueous extraction process, however, it still could be implied that by using infusion method, the major portion of active markers remained in the discarded tea powder. Therefore, the infusion process may be considered as poor extraction efficiency method.

For Lot B, the average amount of CA and RA in the aqueous extracts was $0.427 \pm 0.019$ and 7.872 $\pm 0.330 \mathrm{mg}$ per $1 \mathrm{~g}$ of TL tea powder, respectively. When comparing with Lot A, the amount of CA was not significantly different, while the RA content was significantly lower than that of Lot A $(p<0.05)$. The results implied that in addition to the infusion variables, the active contents in the tea solutions may also be considerably affected by the variation of plant material.

From the previous studies, it was reported that the markers or active compounds in plant raw material may be varied greatly due to different growing and processing conditions [28,29]. The alternative use of standardized TL extract could minimize the variations caused by plant material properties and infusion conditions. There would also be benefits in terms of efficacy and quality consistency of the herbal medicines [30]. As a result, the optimal condition for preparation of standardized TL extract should be further investigated. Furthermore, since RA could be degraded during heat-assisted extraction and/or drying processes, alternative methods should be considered. Among these, the freeze-drying technique could be considered as a potential method for the preparation of TL extract, since it addresses the challenge of preserving heat labile components [31].

\section{Conclusions}

To our knowledge, this is the $1^{\text {st }}$ study to optimize infusion condition for TL tea in order to achieve the maximum marker contents, CA and RA. The results demonstrated that with the different infusion conditions, the marker contents varied considerably which may also result in variation in clinical efficacy. In this study, the RSM based on BBD was successfully used to assess the optimal infusion condition for the TL tea. More importantly, although this tea has been used for decades, the relationship between its clinical efficacy and oral dose of TL tea or active markers was still unclear. Once the optimal infusion condition is applied in a clinical study, a dose-response relationship of TL tea will be obtained which could be further used for determining the oral dose of TL aqueous extract.

\section{Acknowledgements}

This work was supported by the Talent Management Program (TM: CP319) and the Faculty of Pharmacy, Mahidol University, Thailand. 
http://wjst.wu.ac.th

\section{References}

[1] National List of Essential Medicines, Available at: http://drug.fda.moph.go.th, acessed May 2018.

[2] S Ussanawarong and T Thesiri. Effect of Thunbergia laurifolia Linn. on detoxication of parathion in rat. Khon Kaen Univ. Res. J. 2001; 6, 3-13.

[3] J Tangpong and S Satarug. Alleviation of lead poisoning in the brain with aqueous leaf extract of the Thunbergia laurifolia (Linn.). Toxicol. Lett. 2010; 198, 83-8.

[4] W Ruangyuttikarn, P Chattaviriya, N Morkmek, S Chuncharunee and N Lertprasertsuke. Thunbergia laurifolia leaf extract mitigates cadmium toxicity in rats. Scienceasia 2013; 39, 19-25.

[5] P Pramyothin, H Chirdchupunsare, A Rungsipipat and C Chaichantipyuth. Hepatoprotective activity of Thunbergia laurifolia Linn extract in rats treated with ethanol: In vitro and in vivo studies. J. Ethnopharmacol. 2005; 102, 408-11.

[6] O Wonkchalee, T Boonmars, C Aromdee, P Laummaunwai, W Khunkitti, K Vaeteewoottacharn, P Sriraj, R Aukkanimart, W Loilome, Y Chamgramol, C Pairojkul, Z Wu, A Juasook and P Sudsarn. Anti-inflammatory, antioxidant and hepatoprotective effects of Thunbergia laurifolia Linn. on experimental opisthorchiasis. Parasitol. Res. 2012; 111, 353-9.

[7] P Suwanchaikasem, C Chaichantipyuth and S Sukrong. Antioxidant-guided isolation of rosmarinic acid, a major constituent, from Thunbergia laurifolia and its use as a bioactive principle for standardization. Chiang Mai J. Sci. 2014; 41, 117-27.

[8] N Ruangpayungsak. 2016, Development of HPLC method for fingerprinting and quantitative analysis of active compounds of Thunbergia Laurifolia leaf extract using chemometric analysis. M.S. Dissertation, Mahidol University, Bangkok, Thailand.

[9] VR Coelho, CG Vieira, LP de Souza, F Moyses, C Basso, DK Papke, TR Pires, IR Siqueira, JN Picada and P Pereira. Antiepileptogenic, antioxidant and genotoxic evaluation of rosmarinic acid and its metabolite caffeic acid in mice. Life Sci. 2015; 122, 65-71.

[10] P Rojsanga, P Sithisarn, K Tanaka, D Mizuki and K Matsumoto. Thunbergia laurifolia extract ameliorates cognitive and emotional deficits in olfactorectomized mice. Pharm. Biol. 2015; 53, 1141-8

[11] S Kondo, AE Omri, J Han and H Isoda. Antidepressant-like effects of rosmarinic acid through mitogen-activated protein kinase phosphatase-1 and brain-derived neurotrophic factor modulation. J. Funct. Foods. 2015; 14, 758-66.

[12] W Thongsaard and C Marsden. Effect of Thunbergia laurifolia extract on extracellular dopamine level in rat nucleus accumbens. J. Med. Assoc. Thai. 2013; 96, 85-9.

[13] W Thongsaard, R Sangpayap and C Marsden. Chronic effect of Thunbergia laurifolia extract and cocaine in rats using behavior model of addiction. J. Med. Assoc. Thai. 2015; 98, 48-52

[14] Rosmarinic acid for smoker dehabituation, Available at: https://patents.google.com/patent/WO2012136317A1/en, acessed May 2018.

[15] Agent For Smoker Dehabituation, Available at: https://patents.google.com/patent/US20120251462, accessed May 2018.

[16] L Barros, M Duenas, MI Dias, MJ Sousa, C Santos-Buelga and IC Ferreira. Phenolic profiles of cultivated, in vitro cultured and commercial samples of Melissa officinalis L. infusions. Food Chem. 2013; 136, 1-8.

[17] TFF da Silveira, AD Meinhart, CA Ballus and HT Godoy. The effect of the duration of infusion, temperature, and water volume on the rutin content in the preparation of mate tea beverages: An optimization study. Food Res. Int. 2014; 60, 241-5.

[18] E Sharpe, F Hua, S Schuckers, S Andreescu and R Bradley. Effects of brewing conditions on the antioxidant capacity of twenty-four commercial green tea varieties. Food Chem. 2016; 192, 380-7.

[19] Z Nikniaz, R Mahdavi, SJ Ghaemmaghami, N Lotfi Yagin and L Nikniaz. Effect of different brewing times on antioxidant activity and polyphenol content of loosely packed and bagged black teas (Camellia sinensis L.). Avicenna J. Phytomed. 2016; 6, 313-21.

[20] JT DiPiro. Concepts in Clinical Pharmacokinetics. American Society of Health-System Pharmacists, Bethesda, 2010 . 
[21] SLC Ferreira, RE Bruns, HS Ferreira, GD Matos, JM David, GC Brandao, EGP da Silva, LA Portugal, PS dos Reis, AS Souza and WNL dos Santos. Box-Behnken design: An alternative for the optimization of analytical methods. Anal. Chim. Acta. 2007; 597, 179-86.

[22] European Pharmacopoeia Commission. European Pharmacopoeia. $8^{\text {th }}$ (eds.), Council of Europe, Europe, 2013.

[23] Association of official analytical chemistry (AOAC). Guidelines for single laboratory validation of chemical methods for dietary supplements and botanicals, Available at: http://www.aoac.org, accessed May 2018.

[24] MF Nishiyama, MAF Costa, AM Costa, CGM Souza, CG Bôer and CK Bracht. Brazilian green tea (Camellia sinensis var assamica): Effect of infusion time, mode of packaging and preparation on the extraction efficiency of bioactive compounds and on the stability of the beverage. Ciênc. Tecnol. Aliment. 2010; 30, 191-6.

[25] JE Cacace and G Mazza. Mass transfer process during extraction of phenolic compounds from milled berries. J. Food Eng. 2003; 59, 379-89.

[26] JR Vergara-Salinas, J Perez-Jimenez, JL Torres, E Agosin, JR Perez-Correa. Effects of temperature and time on polyphenolic content and antioxidant activity in the pressurized hot water extraction of deodorized thyme (Thymus vulgaris). J. Agric. Food Chem. 2012; 60, 10920-9.

[27] SA Makanjuola. Influence of particle size and extraction solvent on antioxidant properties of extracts of tea, ginger, and tea-ginger blend. Food Sci. Nutr. 2017; 5, 1179-85.

[28] YS Lin, YJ Tsai, JS Tsay and JK Lin. Factors affecting the levels of tea polyphenols and caffeine in tea leaves. J. Agric. Food Chem. 2003; 51, 1864-73.

[29] CI Heck and EG de Mejia. Yerba mate tea (Ilex paraguariensis): A comprehensive review on chemistry, health implications, and technological considerations. J. Food Sci. 2007; 72, 138-51.

[30] S Govindaraghavan, NJ Sucher. Quality assessment of medicinal herbs and their extracts: Criteria and prerequisites for consistent safety and efficacy of herbal medicines. Epilepsy Behav. 2015; 52, 363-71.

[31] SP Ishwarya, C Anandharamakrishnan and AGF Stapley. Spray-freeze-drying: A novel process for the drying of foods and bioproducts. Trends Food Sci. Technol. 2015; 41, 161-81. 